\title{
Efeitos do Pronaf sobre a Produção Agrícola Familiar dos Municípios Tocantinenses
}

\author{
Eder Lucinda Pereira ${ }^{1}$ e Jean Santos Nascimento ${ }^{2}$
}

Resumo: Este artigo tem por objetivo avaliar a capacidade do Pronaf de contribuir para a redução do hiato entre o potencial produtivo e o produto efetivo da agropecuária tocantinense. Em termos metodológicos, além das análises descritivas, foram empregadas a regressão linear pela média e a regressão quantílica. A pesquisa concentrou-se no estado do Tocantins, abarcando todos os municípios (unidades de análise), no período de 2002 a 2009. Foram evidenciadas a importância relativa do setor agrícola para a economia tocantinense, a forte participação da agricultura familiar na produção total do setor e a significativa presença do Pronaf, que, para além de contribuir no processo de legitimação da agricultura familiar, como ressaltado em estudos anteriores, se mostrou capaz de estimular a produção vegetal e animal dos municípios estudados. Além disso, dadas as especificidades do Pronaf no Tocantins, em termos de cobertura e distribuição dos recursos, supõe-se que as constatações confiram ao programa características para também contribuir no processo de redução da desigualdade no estado. Entretanto, adverte-se que, embora o programa mereça a atenção dos formuladores de políticas, dada sua capacidade de estimular a produção agrícola municipal, deve-se concebê-lo como uma intervenção de caráter complementar, já que o trabalho familiar, como registrado na literatura, se mostrou decisivo no desempenho produtivo da agricultura familiar.

Palavras-chaves: Pronaf, agricultura familiar e política pública.

Abstract: This study aimed to evaluate the Pronaf's ability to help reducing the gap between potential yield and actual output of agriculture in Tocantins. In terms of methodology, in addition to descriptive analyses, linear regression of the average and quantile regression were used. The research focused on Tocantins State, covering all municipalities (units of analysis), from 2002 to 2009. It was highlighted: the relative importance of agriculture for the economy in Tocantins, the significant participation of family agriculture in total industry output and the significant presence of Pronaf, which, apart from helping the

1. Mestre em Desenvolvimento Regional pelas Universidades Federais do Tocantins e de Minas Gerais (UFT/UFMG). Economista do Instituto Nacional de Colonização e Reforma Agrária (Incra) e professor de economia da Universidade Federal do Tocantins. E-mail: ederlucinda@hotmail.com

2. Doutor em Economia Aplicada pela Universidade Federal de Viçosa. Professor do Departamento de Economia da Universidade Federal de Campina Grande. E-mail: jean.sn@gmail.com 
process of legitimizing the family farm, as noted in early studies, has been shown capable to stimulate the production of plant and animal municipalities. Moreover, given the specificities of Pronaf in Tocantins, in terms of coverage and resource allocation, it is assumed that the findings give the program characteristics that also contribute for the process of reducing inequality in the state. However, although the program deserves the attention of policy makers, given their ability to stimulate local agricultural production, one must conceive it as a complementary intervention, since the family work, as recorded in literature, proved to be crucial in the productive performance of family farming.

Key-words: Pronaf, familiar agriculture and public policy.

Classificação JEL: Q14, Q18.

\section{Introdução}

Como amplamente discutido na literatura especializada ${ }^{3}$, a agricultura familiar esteve historicamente excluída do processo de desenvolvimento da agricultura brasileira, intensificado a partir dos anos 1960. Além da ausência de delimitação conceitual do agricultor familiar, imprescindível para promovê-lo a público-alvo de política pública, desde a referida década, os incentivos do Estado brasileiro ao setor agrícola foram concentrados no segmento das grandes propriedades rurais, fortalecendo a produção destinada ao mercado externo com o objetivo de melhorar os saldos da balança comercial. Por consequência, esses fatores relegaram para segundo plano qualquer política pública que pudesse contemplar a parte expressiva do setor agrícola composta pela agricultura familiar.

Nos anos 1990, a síntese do conflito político e a consolidação conceitual do termo "agricultura familiar" engendraram a possibilidade de desenvolvimento de políticas públicas específicas para o referido segmento rural. Assim, em 1996, foi instituído o Programa Nacional de Fortalecimento da Agricultura Familiar (Pronaf), com a finalidade de contribuir para o desenvolvimento dos agricultores familiares de modo sustentável, facilitando o

3. Ver, por exemplo, Mattei (2001), Guanziroli et al. (2001), Buainain et al. (2003) e Delgado (2005). aumento da capacidade produtiva, a geração de empregos e a melhoria de renda ${ }^{4}$. No Tocantins, entre 2002 e 2009, o montante de recursos movimentado pelo programa atingiu a média anual de R\$ 103 milhões, alcançando, no período, todos os 139 municípios (SAF/MDA, 2012).

Entretanto, esses dados sobre a dimensão do programa ainda se revelam acanhados diante da importância da agricultura familiar para a economia estadual. De modo semelhante aos dados nacionais, o segmento ocupa cerca de $70 \%$ da mão de obra rural, responde por 35,8\% do valor da produção agropecuária e tem grande participação na produção de alimentos (IBGE, 2009).

De modo geral, todo o setor agropecuário desempenha papel crucial na sustentação da economia tocantinense. Sua importância para o estado pode ser evidenciada usando como referência o conjunto da economia brasileira, pois, enquanto neste caso o valor adicionado bruto da agropecuária tem participação de 5,6\% no valor adicionado bruto total, no Tocantins, essa participação alcança a marca de 20,6\% (IBGE, 2012). Mas, apesar dessa relevância econômica do setor agrícola na economia tocantinense, observa-se que, atualmente, pouco mais da metade do total de terras com potencial para o desenvolvimento da agropecuária se encontra em atividade produtiva, sendo 7,5 milhões de hectares ocupados

4. Conforme Decreto n. 1.946/1996 (BRASIL, 1996). 
pela pecuária e 700 mil hectares, pela agricultura, restando, portanto, vasta extensão de terras $(5,7$ milhões de hectares) para futura expansão da fronteira agrícola (SIC, 2012).

Essas considerações iniciais evidenciam a importância relativa da produção agropecuária na economia do estado do Tocantins, a significativa participação da agricultura familiar nessa produção, a forte expansão do Pronaf no estado e a existência de um importante hiato entre o potencial produtivo e o produto efetivo da agropecuária tocantinense. Diante dessas constatações, questiona-se: seria o Pronaf uma política pública capaz de contribuir para a redução desse hiato entre o potencial produtivo e o produto efetivo da agropecuária tocantinense?

Em geral, os trabalhos que se dedicam a relacionar a dinâmica do crédito concedido pelo programa com variáveis das dimensões econômica e social, além de escassos, têm apresentado resultados divergentes, variando de acordo com a localização do agricultor familiar. No caso da região Norte do País e, em especial, no estado do Tocantins, ainda não há informações suficientes sobre os efeitos do programa (MATTEI, 2006). Nesse sentido, ampliar o conhecimento sobre o Pronaf, consideradas as especificidades regional/ local ${ }^{5}$, pode produzir, para além da mera constatação de suas virtudes ou fracassos, importantes subsídios para intervenções futuras que tenham como objetivo aperfeiçoar a referida política pública.

\section{Fundamentação teórica}

\subsection{Crédito e desenvolvimento}

A influência do mercado de crédito no desenvolvimento das atividades produtivas já mereceu a atenção de diversos estudiosos. Schumpeter (1997) considera que, em uma sociedade em que prevalecem a propriedade privada dos meios de produção e a divisão do trabalho, o desen-

5. Mattei (2005) já demonstrava preocupação com a necessidade de estudos que abordassem os impactos do Pronaf em economias locais. volvimento só se torna viável por meio do crédito. Nessa perspectiva schumpeteriana, o crédito é visto como elemento essencial no processo de desenvolvimento ao possibilitar o financiamento de novas combinações dos fatores de produção (inovações produtivas).

No caso específico do setor agropecuário brasileiro, considera-se crédito rural o montante de recursos financeiros disponibilizados por instituições pertencentes ao Sistema Nacional de Crédito Rural (SNCR), destinados a estimular o desenvolvimento de atividades ligadas ao setor rural da economia. Segundo Bacha (2004), dadas as características peculiares do setor agrícola, especialmente no que se refere às condições climáticas e de preço, para o seu desenvolvimento, são necessárias políticas que estimulem o agricultor a produzir e, ao mesmo tempo, reduzam o risco do investimento agrícola, que tende a ser maior que o do investimento industrial. No caso da agricultura familiar, para Conti e Roitman (2011), além de serem fundamentais políticas públicas de assistência técnica e de aquecimento da demanda, o crédito é realmente crucial. Para além da dimensão estritamente produtiva, Sacco dos Anjos et al. (2004) destacam a importância do crédito agrícola como ferramenta a ser utilizada na busca por desenvolvimento e justiça social.

No Brasil, o SNCR foi instituído em 1965, ampliando o volume de crédito concedido no País e estabelecendo a obrigatoriedade de as instituições financeiras que integram o referido sistema destinarem ao setor rural determinada proporção dos recursos transacionados, uma que vez que, sujeito ao arbítrio do mercado, o segmento rural sofria com a escassez de financiamento (CONTI e ROITMAN, 2011). Entretanto, seguindo orientação do próprio governo federal, durante os anos de 1970/80, o crédito rural privilegiou os médios e grandes produtores das regiões Sul e Sudeste, que destinavam seus produtos ao mercado externo. Além de a diretriz macroeconômica do governo ser favorável aos produtores ligados à exportação, esse segmento era também preferido pelo setor bancário, pois tomava empréstimos mais vultosos - o que oferecia maior margem 
de lucro - e também detinha a propriedade legal de suas terras, que serviam de garantia real. Neste sentido, Bittencourt (2003) ressalta que o SNCR financiou o processo de modernização da base técnica da agricultura. E mais que isso, o autor observa que, como a liberação do crédito estava atrelada ao uso de "pacotes tecnológicos", a política de fato beneficiava um grupo restrito de agricultores, o que ampliou as desigualdades de renda entre agricultores e também entre regiões.

Como participantes de um programa de crédito, os agricultores beneficiários do Pronaf devem pagar seus financiamentos por meio dos resultados de suas atividades produtivas. No entanto, apesar de desenvolverem atividades rentáveis, o que, em tese, seria suficiente para obter o financiamento da produção pelas vias normais do sistema de crédito rural, isso não ocorria antes da intervenção do Estado por meio do Pronaf, pois a preferência do sistema bancário pelos grandes produtores não reside na rentabilidade de suas atividades (eficiência econômica), mas no fato de gerarem contratos mais vantajosos em termos de contrapartidas financeiras (como seguros, aplicações e outros) e de garantias reais que reduzem o risco da operação. No caso de contratos com baixos valores, o custo da operação bancária tende a superar a rentabilidade esperada, tornando-os pouco atrativos comparativamente às transações de maior vulto. Isso mostra que a expansão do crédito rural via Pronaf, cujos valores médios dos contratos são consideravelmente baixos, só foi possível graças à capacidade da política pública específica de criar um ambiente institucional favorável aos agricultores familiares (ABRAMOVAY e VEIGA, 1999).

\subsection{O Programa Nacional de Fortalecimento da Agricultura Familiar (Pronaf)}

Com a consolidação do Pronaf, o ambiente institucional $^{6}$ em que estava inserida a polí-

6. Nessa perspectiva, as instituições são entendidas como "as regras do jogo numa sociedade", que norteiam o comportamento dos agentes econômicos, que delimitam as "interações sociais". Essas regras podem ser de natureza formal ou tica nacional de crédito, assim como a dimensão do papel da agricultura familiar no processo de desenvolvimento rural, foram significativamente modificados. Por um lado, as mudanças nas regras do jogo permitiram diretamente que a agricultura familiar tivesse maior inserção no mercado de crédito. Por outro, a criação de novos espaços de ação política, de interação social, contribuiu para ampliar a compreensão sobre a importância da agricultura familiar tanto no âmbito dos governos quanto da sociedade em geral. As novas instâncias de representação e gestão social, consubstanciadas, por exemplo, nos conselhos, possibilitaram que os agricultores participassem ativamente da política pública ${ }^{7}$ nas três esferas de governo.

Uma das primeiras avaliações do programa foi feita por Abramovay e Veiga (1999), contemplando principalmente as ações voltadas para o financiamento. No entendimento dos autores, o programa teria a finalidade de compensar uma falha de mercado que age em desfavor do agricultor familiar, fragilizando um segmento economicamente importante, sobretudo na ocupação de mão de obra e geração de renda. A referida falha de mercado consistiria na ausência de infraestrutura que favorecesse a produção familiar nos municípios, bem como na dificuldade de acesso a financiamento via mercado devido às costumeiras exigências de garantias ${ }^{8}$. Outra importante constatação de Abramovay e Veiga (1999) foi a forte concentração dos recursos do Pronaf na região Sul e na parte Sul de Minas Gerais. Essa concentração decorre justamente da ação das forças de mercado, que cuidam de selecionar agricultores mais integrados e com menor risco de inadimplência. Dessa forma, fatalmente, o crédito escorre para mercados mais dinâmicos, bus-

informal, o importante é que elas condicionam a ação dos indivíduos (NORTH, 1994; ABRAMOVAY e VEIGA, 1999).

7. North (1994) destaca que a literatura tem registrado com frequência a importância de espaços onde os agricultores tenham a oportunidade de interagir com cientistas e autoridades.

8. No caso do Tocantins, além da exigência da garantia real, foi relatada alta burocracia no processo de concessão do crédito (ABRAMOVAY e VEIGA, 1999). 
cando agricultores mais fortes do ponto de vista econômico, quais sejam: aqueles ligados aos complexos agroindustriais ${ }^{9}$ - e que por isso possuem facilidades de comercialização -, bem como aqueles que podem apresentar garantias contratuais aos bancos.

Kageyama (2003), trabalhando com dados de oito estados brasileiros, chegou à conclusão de que o Pronaf não estava associado à maior renda familiar, mas que, por outro lado, existia forte correlação entre o programa e variáveis tecnológicas e de produtividade agrícola. Assim, ao mesmo tempo em que a inexistência de associação positiva entre o Pronaf e a renda causa certa frustração, uma vez que este é um de seus principais objetivos, o aumento indiscriminado do aparato tecnológico traz a preocupação de que o Pronaf esteja reproduzindo a mesma lógica do chamado modelo produtivista ${ }^{10}$ o que também estaria contrariando seus propósitos de intervenção no desenvolvimento rural sustentável. Reforça essa hipótese a associação positiva do Pronaf com a erosão e com a frequência do uso de agrotóxicos. Essa preocupação de que o programa se desvie das orientações iniciais e acabe privilegiando agricultores que se enquadrem em preceitos puramente produtivistas foi também manifestada por Gazolla e Schneider (2005), Aquino e Teixeira (2005) e por Mattei (2005 e 2006).

Silva e Alves Filho (2009) ressaltam a capilaridade do Pronaf e sua decorrente importância para o desenvolvimento rural e territorial. Os autores detectaram impactos positivos do Pronaf em variáveis econômicas (PIB total e setorial) dos municípios que compõem o Médio Jequitinhonha, em Minas Gerais. Observaram, ainda, que, apesar de o Pronaf ser uma política agrícola, os impactos verificados no PIB de serviços e no PIB industrial superavam os do PIB agropecuário, sugerindo

9. Mais detalhes podem ser obtidos em Aquino e Teixeira (2005), Sacco dos Anjos et al. (2004) e em Mattei (2005).

10. Segundo Aquino e Teixeira (2005), pelo discurso governamental que envolveu a criação do Pronaf, esperava-se que ele fosse capaz de reduzir desigualdades, extrapolando a esfera produtiva. Para Sacco dos Anjos et al. (2004), o Pronaf tem compromissos como a inclusão social, a geração de empregos e o desenvolvimento territorial. aquisição de bens de consumo e serviços não ligados ao processo produtivo - o que não causaria surpresa, dado o nível de renda dos agricultores do território estudado.

Ao analisar os 100 municípios que mais receberam recursos do Pronaf entre 2001 e 2004, Mattei (2005), além de atribuir ao Pronaf virtudes como a descentralização das políticas públicas do setor agrícola e a geração de sinergias entre as esferas públicas e organizações da sociedade civil, o associa ao aumento da produção, da área colhida, do nível de emprego e da arrecadação municipal. Entretanto, uma das limitações dessa avaliação consiste no fato de, dos 100 municípios considerados, $82 \%$ deles pertencerem à região Sul do País. Esses municípios da região Sul concentraram $85 \%$ dos recursos e $90 \%$ dos contratos que integraram o ranking. Além disso, apenas os municípios gaúchos responderam por $58 \%$ do montante de recursos e por $49 \%$ dos contratos. Essa concentração do Pronaf, além de outras particularidades sulistas de ordem econômica, política e social, dificulta qualquer extrapolação dos resultados para outras regiões.

Posteriormente, Mattei et al. (2007) abordaram exclusivamente o desempenho do programa nas regiões Norte, Nordeste e Centro-Oeste, estimando, para tanto, seus efeitos sobre variáveis representativas das dimensões produtiva, demográfica, social e tributária. De modo geral, nas três regiões, constatou-se associação positiva, apesar de fraca, entre o volume de crédito do Pronaf e a maioria das variáveis analisadas, sobretudo em 2004. Assim, os resultados sugerem também a evolução positiva dos efeitos do programa entre 2001 e 2004. Em todos os casos houve destaque dos efeitos sobre as variáveis da dimensão produtiva em relação às demais.

Na avaliação de Magalhães et al. (2006), um dos principais objetivos do programa de crédito seria a redução da pobreza que acomete boa parte dos agricultores familiares do Brasil. Nessa perspectiva, ressaltam que "o programa busca assegurar o acesso ao crédito barato a pequenos produtores, além de integrá-los a outras políticas de desenvolvimento rural, como suporte ao 
desenvolvimento de infraestrutura e assistência técnica" (MAGALHÃES et al., 2006, p. 58). A redução da pobreza de fato seria uma função importante do programa, pois, apesar de hoje a maioria dos pobres no Brasil estar localizada na rede urbana, em termos relativos, nas regiões Norte e Nordeste, a zona rural apresenta proporções mais elevadas de pobres (GOLGHER e MARQUES, 2006). Entretanto, os resultados encontrados pelo autor para o Pronaf pernambucano não foram muito animadores, uma vez que seus impactos sobre renda e produtividade foram pouco significativos ou até mesmo negativos.

Não obstante, se o Pronaf de fato contribuísse para a redução da pobreza rural era de se esperar que ele também contribuísse para a retenção da população rural no campo. Entretanto, a literatura tem apresentado exemplos distintos de efeitos do Pronaf sobre a decisão dos agricultores de permanecerem ou não na zona rural, em suas parcelas de terra de origem. Em alguns casos, verifica-se associação positiva entre o crescimento do volume de crédito do programa e a manutenção (ou até crescimento) da população rural (GASQUES et al., 2005). Já em outros, essa relação não foi verificada, havendo situações em que o Pronaf financia a saída da população do campo, caso, por exemplo, das migrações temporárias no Norte e Nordeste do Brasil (FRAZÃO FILHO e MORAES, 2010).

Nessa breve revisão da literatura relativa ao Pronaf, é possível verificar que existe certo consenso entre os pesquisadores de que o programa representa uma guinada no ambiente institucional em favor da agricultura familiar. A despeito disso, os estudos que se propõem a mensurar seu desempenho, em especial seus efeitos sobre a dimensão produtiva, apresentam resultados divergentes e não permitem generalizações ${ }^{11}$. Pelo contrário, os trabalhos sugerem que os resultados do programa dependem significativamente das condições locais do público beneficiário, variando, assim, em função da base territorial.

11. Uma síntese de avaliações sobre o Pronaf, incluindo resultados negativos e positivos, pode também ser encontrada em Guanziroli (2007).

\section{A agricultura familiar no Tocantins}

O Censo Agropecuário de 2006 contribuiu muito para o dimensionamento da agricultura familiar ${ }^{12}$ ao permitir, para algumas variáveis, a segregação entre agricultura familiar e não familiar. Essa inovação ${ }^{13}$, além de colaborar com o processo de legitimação do segmento familiar, abriu um leque de possibilidades para pesquisas que forneçam subsídios para o aperfeiçoamento de políticas públicas específicas para a agricultura familiar.

De acordo com o referido Censo Agropecuário de 2006 (IBGE, 2009), no Tocantins, a agricultura familiar detém 42.899 estabelecimentos rurais (76\% do total) e ocupa área de 2,7 milhões de hectares (18,9\% do total). Em média, cada estabelecimento familiar ocupa 63,8 ha contra 848,5 ha da agricultura não familiar. Assim, em média, a área de um estabelecimento da agricultura familiar no Tocantins ocupa 7,4\% da área de um estabelecimento não familiar. Em termos de produção, mesmo ocupando apenas $18,9 \%$ da área total, a agricultura familiar do estado gera R\$ 273,7 milhões em receitas (35,8\% do total) e ocupa 122.936 pessoas $(69,5 \%$ do total). Observa-se que a produção familiar se concentra, sobretudo, na produção de alimentos, inclusive para o autoconsumo, e tem como importante fator de produção a própria mão de obra familiar.

Na produção animal, os principais rebanhos são de bovinos e suínos. A atividade leiteira e a produção de aves são também relevantes tanto como alimentos para o autoconsumo quanto na geração de renda. A produção vegetal, que se subdivide em lavouras temporárias e permanentes,

12. O Censo Agropecuário de 2006 pode conter pequena superestimação da agricultura familiar em virtude de considerar cada estabelecimento como uma unidade familiar. Contudo, essa diferença tende a não ser muito significativa, pois, segundo a PNAD 2007, agricultores com mais de um estabelecimento representavam apenas $0,8 \%$ do total (IBGE, 2009).

13. Trabalhos anteriores, a exemplo de Guanziroli et al. (2001), estimaram as dimensões da agricultura familiar no Brasil com base no Censo Agropecuário de 1995/96, mas apenas no Censo Agropecuário de 2006 o segmento foi de fato investigado (IBGE, 2011). 
tem como sustentáculo as culturas temporárias, sobretudo, o arroz, o milho, a mandioca e o feijão. Em termos de produtividade do fator terra, a agricultura familiar superou a agricultura não familiar na produção de mandioca e milho e foi superada nas culturas de arroz e feijão (IBGE, 2012).

A maior concentração de estabelecimentos familiares no Tocantins ocorre na Microrregião Geográfica de Miracema do Tocantins, que abriga 8.229 estabelecimentos (21\%), seguida pelas microrregiões do Bico do Papagaio (16,8\%), Araguaína (16,0\%), Dianópolis (14,5\%) e Jalapão (10,3\%). Já as microrregiões de Gurupi, Porto Nacional e Rio Formoso apresentam as menores participações no número total de estabelecimentos com, respectivamente, 7\%, 7,9\% e 8,4\% (IBGE, 2012). Em algumas microrregiões, observa-se correspondência entre os estabelecimentos familiares e a distribuição dos Projetos de Assentamento da Reforma Agrária, o que era de se esperar, dado o fato de a maior parte dos assentados pela reforma agrária se enquadrar na categoria de agricultores familiares e o Tocantins possuir grande número de famílias assentadas (23.513, em 2012) ${ }^{14}$.

A produção da agricultura familiar é sabidamente intensiva no fator trabalho - que se consubstancia, sobretudo, na mão de obra da própria família - sendo este atributo fundamental para a identificação do segmento produtivo e da categoria social de agricultor familiar. Mas, mais que isso, segundo FAO/Incra (2000), dadas as características do segmento, pode-se considerar que o trabalho familiar representa, com razoável precisão, o total da carga de trabalho utilizada na produção do estabelecimento. No caso do Tocantins, ao confrontar a produção com a mão de obra familiar disponível, observou-se considerável correspondência entre essas duas variáveis. Percebe-se, na maioria das microrregiões tocantinenses, que a produção, tanto vegetal quanto animal, tende a acompanhar a disponibilidade de mão de obra familiar, ou seja, as microrregiões que mais produzem tendem a ser aquelas com maior estoque do fator de produção trabalho familiar.

14. Conforme Incra (2012).
Em 2006, a produção vegetal da agricultura familiar no Tocantins foi de 188,5 mil toneladas. Entre as microrregiões, em termos de volume de produção, ocupa o primeiro lugar a Microrregião de Rio Formoso (20,8\%), sendo também a microrregião com maior discrepância entre produção e dotação de mão de obra familiar, o que sugere um processo de alteração da base técnica de produção mais avançado nessa microrregião. A Microrregião do Bico do Papagaio, com a maior dotação de mão de obra em lavouras temporárias $(22,9 \%)$, contribui com $18,8 \%$ e, a de Dianópolis, com 16,2\%. Com participações mais acanhadas aparecem, nesta ordem, as microrregiões do Jalapão (13,6\%), Miracema do Tocantins $(11,3 \%)$, Araguaína $(8,6 \%)$, Gurupi $(5,4 \%)$ e Porto Nacional $(5,2 \%)$. Verifica-se, nas microrregiões de Dianópolis, Gurupi, Jalapão e Miracema do Tocantins, correspondência quase perfeita entre produção vegetal e disponibilidade de mão de obra familiar para lavouras temporárias. No caso da produção pecuária, em 2006, a receita total do estado foi de R\$115,2 milhões, tendo destaque, em termos de valor da produção, as microrregiões de Miracema do Tocantins $(21,5 \%)$ e Araguaína (20,2\%), seguidas do Bico do Papagaio $(17 \%)$, de Dianópolis $(11 \%)$ e de Rio Formoso (9,9\%). Com as menores participações ficam, nesta ordem, Gurupi $(8,4 \%)$, Jalapão $(6,7 \%)$ e Porto Nacional (5,5\%) (IBGE, 2012).

\section{Metodologia}

\subsection{Escopo da pesquisa}

Neste artigo, avaliou-se a capacidade do Pronaf, como política pública, de contribuir para a redução do hiato entre o potencial produtivo e o produto efetivo da agropecuária tocantinense. $\mathrm{O}$ estudo restringiu-se ao estado do Tocantins, contemplando a abrangência do programa e a distribuição de seus recursos entre 2002 e 2009, bem como os efeitos do Pronaf sobre variáveis da produção agrícola de origem familiar em 2006 nos 139 municípios tocantinenses (unidades de 
Quadro 1. Variáveis utilizadas nas análises das regressões

\begin{tabular}{|l|l|c|c|c|}
\hline \multicolumn{2}{|c|}{ Variáveis dependentes } & Unidade & Período & Fonte \\
\hline Valor da produção da lavoura temporária & $\ln ($ valorLT) & $\mathrm{R} \$$ & 2006 & IBGE \\
\hline Produção vegetal & $\ln (\mathrm{pPV})$ & $\mathrm{t}$ & 2006 & $\mathrm{IBGE}$ \\
\hline Valor da produção animal & $\ln ($ valorPA) & $\mathrm{R} \$$ & 2006 & $\mathrm{IBGE}$ \\
\hline Valor da produção de animais de grande porte & $\ln ($ valorAGP) & $\mathrm{R} \$$ & 2006 & $\mathrm{IBGE}$ \\
\hline \multicolumn{2}{|c|}{ Variáveis Explicativas } & Unidade & Período & Fonte \\
\hline \multicolumn{2}{|c|}{ Pronaf } & $\ln$ R $\$$ & 2006 & SAF/MDA \\
\hline Mão de obra familiar em lavouras temporárias & $\ln (\mathrm{mobLT})$ & pessoas & 2006 & IBGE \\
\hline Mão de obra familiar na pecuária e outros animais & $\ln (\mathrm{mobPA})$ & pessoas & 2006 & IBGE \\
\hline
\end{tabular}

análise). Para tanto, além das análises descritivas, foram empregadas a Regressão Linear pela Média (RLM) e a Regressão Quantílica (RQ), que serão detalhadas a seguir.

\subsection{Variáveis e dados}

Conforme detalhado no Quadro 1, as variáveis utilizadas no estudo são exclusivas da agricultura familiar, quais sejam: valor da produção de lavoura temporária ${ }^{15}$, volume da produção vegetal ${ }^{16}$, valor da produção animal ${ }^{17}$, valor da produção de animais de grande porte, mão de obra familiar alocada em lavouras temporárias, mão de obra familiar alocada na produção animal e volume de crédito do Pronaf ${ }^{18}$. As variáveis

15. As lavouras temporárias, Tabela n. 1.118 do Censo Agropecuário de 2006, incluem "culturas de curta ou média duração, geralmente com ciclo vegetativo inferior a um ano, que, após a colheita, necessitam de novo plantio para produzir", sendo exemplos a mandioca, o feijão, o milho e o arroz. Já as lavouras permanentes se caracterizam pelo "longo ciclo vegetativo, que permite colheitas sucessivas sem necessidade de novo plantio", sendo exemplos o café, o cacau e o palmito (IBGE, 2012).

16. A produção vegetal, Tabela n. 949 do Censo Agropecuário de 2006, inclui lavouras temporárias e permanentes: arroz, milho, mandioca, feijão, soja, café e trigo. No Tocantins, em termos de área colhida, a produção vegetal da agricultura familiar está dividida da seguinte forma: arroz, $50 \%$; milho, $30,6 \%$; mandioca, $8 \%$; feijão, $7,2 \%$ e soja, $4,2 \%$ (IBGE, 2012).

17. A produção animal, Tabela n. 1.118 do Censo Agropecuário de 2006, inclui animais de grande, médio e pequeno porte. Animais de grande porte: "bovinos, bubalinos, equinos, asininos e muares. Animais de médio porte: suínos, caprinos e ovinos. Animais de pequeno porte: aves e coelhos" (IBGE, 2012).

18. Inclui todas as linhas de crédito voltadas ao financiamento da produção. de produção e dotação de mão de obra familiar foram extraídas do Censo Agropecuário de 2006 e a variável volume de crédito do Pronaf foi obtida na Secretaria de Agricultura Familiar (SAF) do Ministério de Desenvolvimento Agrário (MDA).

As lavouras temporárias constituem importante variável na avaliação de desempenho do programa por dois motivos. De um lado, pela forte participação da agricultura familiar na produção total dessas culturas. De outro, porque, como salientado por Mattei et al. (2007), são as lavouras temporárias que melhor refletem os efeitos de curto prazo do crédito. Nesse ponto, é também importante ressaltar que a variável produção vegetal, da forma como é definida pelo IBGE, constitui no Tocantins um subgrupo bastante restrito da variável lavouras temporárias. Essa é uma especificidade do estado por não possuir lavouras significativas de café e trigo, o que torna a variável produção vegetal de suma importância analítica, pois, com exceção da soja, as demais lavouras que a integram - arroz, milho, mandioca e feijão - ocupam grande parte do esforço produtivo da agricultura familiar.

Já a produção animal representa a maior fonte de receita do conjunto de municípios tocantinenses. Nesta variável está incluída a produção de animais de grande porte que, na média dos municípios tocantinenses, representa cerca de $80 \%$ da receita total da produção animal. Além disso, essa produção de animais de grande porte do estado, na qual se destaca a criação de bovinos, conta com a participação de todos os municípios. 
No que se refere às variáveis explicativas, além do volume de crédito do Pronaf, foi incluída a variável mão de obra familiar, subdivida em mão de obra dedicada às lavouras temporárias e mão de obra voltada à produção animal. A inclusão justifica-se por ser o trabalho da própria família decisivo no resultado produtivo do segmento, sendo inclusive fundamental no conjunto das características que definem o agricultor como familiar ${ }^{19}$.

\subsection{Métodos de estimação e modelos analíticos}

\subsubsection{A regressão linear pela média}

A análise de Regressão Linear pela Média (RLM) tem por finalidade estimar coeficientes que expressem a relação entre uma variável dependente e duas ou mais variáveis explicativas (independentes). No caso de duas variáveis explicativas, o modelo de regressão estima a média condicional (valor esperado) de $Y$, condicionado a valores fixos de $X_{1}$ e $X_{2}$ (GUJARATI, 2006).

Nesta pesquisa, foram estimados coeficientes entre o volume de crédito do Pronaf e a mão de obra familiar (variáveis explicativas) e diversas variáveis da produção agrícola familiar (variáveis dependentes), tendo por objetivo estimar a relação entre o volume de crédito do Pronaf e cada uma das variáveis de produção da agricultura familiar.

Os modelos econométricos foram especificados em duplo-log, de modo que os coeficientes medem elasticidades, ou seja, a variação percentual na variável dependente, dada uma variação percentual nas variáveis explicativas (Pronaf ou mão de obra familiar). Para obter as estimativas dos coeficientes das regressões, foi utilizado o pacote estatístico Stata (versão 12.1).

Os modelos utilizados na análise estão dispostos a seguir segundo o efeito dos recursos do Pronaf [ln(pronaf)] e da mão de obra familiar

19. Sobre o trabalho da família no âmbito da unidade de produção familiar, consultar, por exemplo, FAO/Incra (2000), Buainain et al. (2003), Schneider (2003) e Abramovay (1992).
- $\ln (m o b L T)$ quando a variável dependente pertencer à agricultura ou $\ln (m o b P A)$ quando a variável dependente for da pecuária - sobre variáveis específicas da produção agrícola familiar.

Valor da produção de lavoura temporária:

$\ln (\text { valorLT })_{i}=\alpha_{0}+\alpha_{1} \ln (\text { pronaf })_{i}+\alpha_{2} \ln (\text { mobLT })_{i}+z_{i}$

Produção vegetal:

$\ln (p P V)_{i}=\chi_{0}+\chi_{1} \ln (\text { pronaf })_{i}+\chi_{2} \ln (\text { mobLT })_{i}+x_{i}$

Valor da produção animal:

$\ln (\text { valor } P A)_{i}=\varepsilon_{0}+\varepsilon_{i} \ln (\text { pronaf })_{i}+\varepsilon_{2} \ln (m o b P A)_{i}+v_{i}$

Valor da produção de animais de grande porte: $\ln (\text { valor } A G P)_{i}=\phi_{0}+\phi_{i} \ln (\text { pronaf })_{i}+\phi_{2} \ln (\text { mobP } A)_{i}+u_{i}$

Em que: $\alpha_{0}, \alpha_{1}, \alpha_{2}, \chi_{0}, \chi_{1}, \chi_{2}, \varepsilon_{0}, \varepsilon_{1}, \varepsilon_{2}, \phi_{0}, \phi_{1}$, $\phi_{2}$ são os coeficientes a serem estimados; $\ln (\text { valorLT })_{i}$, $\ln (p P V)_{i}, \ln \left(\right.$ valor $P A{ }_{i}, \ln (\text { valor } A G P)_{i}$, são os logaritmos naturais do valor da produção de lavoura temporária; do volume da produção vegetal; do valor da produção animal; do valor da produção de animais de grande porte; e $z_{i}, x_{i}, v_{i}$ e $u_{i}$, são os termos de erro idiossincráticos.

\subsubsection{A regressão quantílica}

O modelo de Regressão Quantílica (RQ), por utilizar a mediana condicional como medida de tendência central, revela-se mais apropriado quando a distribuição de probabilidade da variável resposta é assimétrica (HAO e NAIMAN, 2007). Assim sendo, levando-se em conta que as variáveis dependentes selecionadas apresentam grande desigualdade entre os municípios do estado, a análise por meio da RQ mostrou-se mais adequada que a realizada por meio da RLM, que será mantida nas tabelas de resultados das regressões apenas como referência. As variáveis utilizadas nesta análise são as mesmas da RLM (Quadro 1).

No caso concreto, por meio da RQ tornou-se possível observar os efeitos das variáveis explicativas (Pronaf e mão de obra familiar) ao longo de toda distribuição de probabilidade das variáveis dependentes, o que aumentou a capacidade analítica dos modelos, uma vez que, como men- 
cionado, os dados da produção familiar dos 139 municípios são discrepantes.

Também neste caso, a exemplo do que ocorreu nas regressões pela média, os modelos econométricos foram especificados em duplo-log, de modo que os coeficientes medissem elasticidades obtidas por meio do pacote estatístico Stata (versão 12.1). Ainda de modo similar, os modelos utilizados na análise estão dispostos a seguir, segundo o efeito dos recursos do Pronaf $[\ln ($ pronaf $)]$ e da mão de obra familiar $-\ln ($ mobLT $)$ quando a variável dependente pertencer à agricultura ou $\ln (m o b P A)$ quando a variável dependente for da pecuária - sobre variáveis específicas da produção agrícola familiar.

Valor da produção de lavoura temporária:

$\ln (\text { valor } L T)_{i}^{(p)}=\alpha_{0}^{(p)}+\alpha_{1} \ln (\text { pronaf })_{i}^{(p)}+\alpha_{2} \ln (\text { mobLT })_{i}^{(p)}+z_{i}^{(p)}$

Produção vegetal:

$\ln (p P V)_{i}^{(p)}=\chi_{0}^{(\rho)}+\chi_{1} \ln (\text { pronaf })_{i}^{(\rho)}+\chi_{2} \ln (\text { mobLT })_{i}^{(\rho)}+x_{i}^{(p)}$

Valor da produção animal:

$\ln (\text { valorP } A)_{i}^{(p)}=\varepsilon_{0}^{(p)}+\varepsilon_{1} \ln (\text { pronaf })_{i}^{(p)}+\varepsilon_{2} \ln (\text { mobP } A)_{i}^{(\rho)}+v_{i}^{(\rho)}$

Valor da produção de animais de grande porte:

$\ln (\text { valor } A G P)_{i}^{(p)}=\phi_{0}^{(p)}+\phi_{i} \ln (\text { pronaf })_{i}^{(p)}+\phi_{2} \ln (m o b P A)_{i}^{(p)}+u_{i}^{(p)}$

Em que: $\alpha_{0}, \alpha_{1}, \alpha_{2}, \chi_{0}, \chi_{1}, \chi_{2}, \varepsilon_{0}, \varepsilon_{1}, \varepsilon_{2}, \phi_{0}, \phi_{1}, \phi_{2}$ são os coeficientes a serem estimados; $\ln ($ valorLT) ${ }_{i}, \ln (p P V)_{i}, \ln \left(\right.$ valorPA $_{i}, \ln (\text { valor } A G P)_{i}$ são os logaritmos naturais do valor da produção de lavoura temporária; do volume da produção vegetal; do valor da produção animal; do valor da produção de animais de grande porte; e $z_{i}, x_{i}, v_{i}$ e $u_{i}$ são os termos de erro idiossincráticos; e $(p)$ indica que se trata de uma regressão quantílica.

\section{Resultados e discussão}

\subsection{Aspectos gerais do Pronaf: Tocantins versus Brasil}

O ritmo da ampliação da cobertura do programa acompanhou a expansão do montante de recursos e do número de contratos assinados. Em 2002, mais de $30 \%$ dos municípios tocantinenses não tinham acesso ao programa. Esse número foi drasticamente reduzido em 2003 e seguiu caindo nos anos subsequentes, para, em 2009, alcançar a quase totalidade dos municípios tocantinenses (138). Embora exista considerável desigualdade na distribuição dos recursos entre os municípios, o fato de o programa estar presente em quase todos já é um grande avanço da política. Como bem registrado por Mattei (2006), uma das virtudes do Pronaf, na condição de política pública, é sua descentralização, conseguindo atingir um número crescente de famílias mesmo nos mais remotos rincões do território nacional.

Em termos regionais, a distribuição dos recursos sempre esteve muito concentrada na região Sul, especialmente no Rio Grande do Sul. Como ressaltado por Aquino e Teixeira (2005), essa é uma das grandes contradições do programa, já que a maior parte de seu público-alvo está na região Nordeste do País. Para Mattei (2005), essa tendência de concentração dos recursos no Sul do País está relacionada ao poder das agroindústrias e à maior capacidade de organização dos agricultores daquela região. Dessa forma, a política que deveria também contribuir para reduzir desigualdades regionais acaba, contraditoriamente, privilegiando municípios de regiões mais ricas em detrimento das mais pobres, como observado por Aquino e Teixeira (2005).

Mesmo considerando o ano de 2006, no qual a região Sul registrou a menor participação no montante de recursos do Pronaf, quando se confronta a distribuição dos estabelecimentos classificados como familiares pelo Censo Agropecuário (IBGE, 2012) com a distribuição dos recursos do programa, observa-se que a referida contradição persiste, sobretudo entre as regiões Sul e Nordeste. Na Figura 1, verifica-se que a grande maioria dos estabelecimentos familiares está na região Nordeste $(50,1 \%)$, enquanto sua participação no total de recursos do Pronaf é de somente $26,6 \%$. Por outro lado, a região Sul, com apenas $19,5 \%$ dos estabelecimentos, abocanha a maior parte dos recursos $(38,2 \%)$. No caso das regiões 
Figura 1. Distribuição dos estabelecimentos da agricultura familiar e dos recursos do Pronaf grandes regiões e Tocantins, 2006

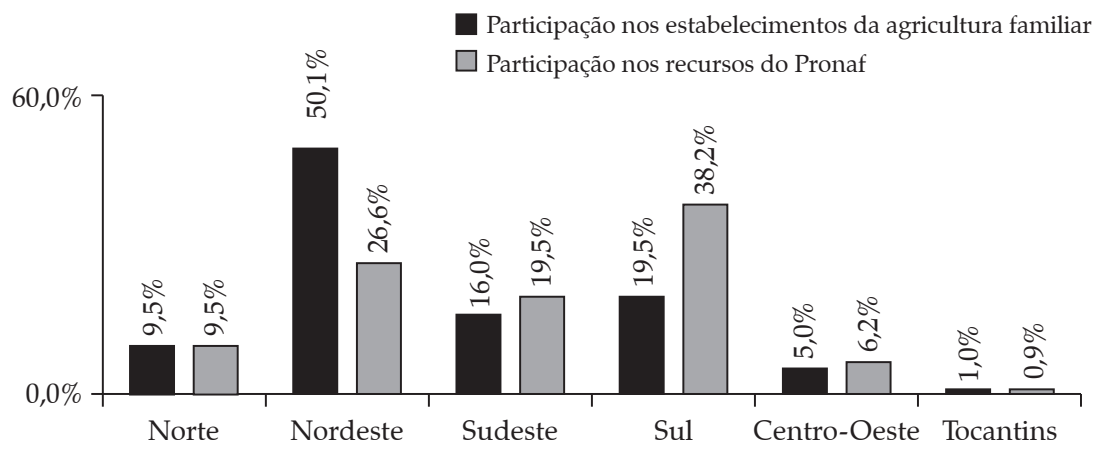

Fonte: Elaboração própria a partir de dados da SAF/MDA (2012) e do Censo Agropecuário de 2006 (IBGE, 2012).

Sudeste e Centro-Oeste, as diferenças são bem menos significativas. Na região Norte, especialmente no estado do Tocantins, as diferenças são pequenas, verificando-se correspondência quase perfeita entre as duas variáveis.

Para Aquino e Teixeira (2005), uma função fundamental do Pronaf seria combater as desigualdades regionais, setoriais e pessoais agravadas pela política conservadora de desenvolvimento da base técnica da agricultura brasileira, que dominou o setor agrícola até o início dos anos 1990. Neste aspecto, algumas especificidades do Pronaf no estado do Tocantins merecem destaque. Observa-se, na Figura 2, por exemplo, que a distribuição dos recursos não favorece as microrregiões mais ricas em detrimento das mais pobres. Comparando dados de 2006, a microrregião mais rica do estado, Porto Nacional, que concentrava $26,2 \%$ do PIB estadual, recebeu apenas $4,9 \%$ dos recursos do programa. Por outro lado, a Microrregião do Bico do Papagaio, uma das mais pobres, contando com 25 municípios, participando com apenas 7,3\% do PIB estadual, recebeu 19,4\% dos créditos do programa. Além disso, verifica-se comportamento bastante semelhante entre as curvas de volume do Pronaf e a de número de Projetos de Assentamento, o que também depõe a favor da focalização do programa, uma vez que os assentados pela reforma agrária se enquadram como beneficiários do programa,

Figura 2. Distribuição do PIB, do PIBagro, Pronaf e dos projetos de assentamento entre as microrregiões geográficas do estado do Tocantins

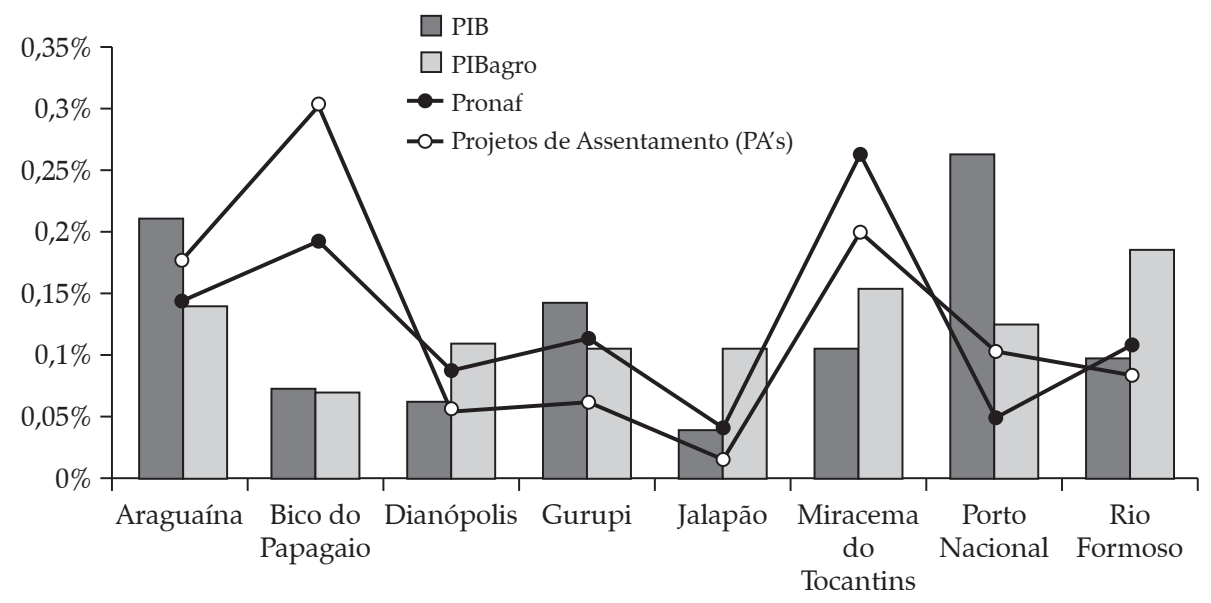

Nota: Dados de 2006. No caso dos Projetos de Assentamento, número acumulado até final de 2006. Fonte: Elaboração própria a partir de dados da SAF/MDA (2012), IBGE (2012) e Incra (2012). 
Tabela 1. Estatísticas descritivas das variáveis, 2006

\begin{tabular}{lcccccccc}
\hline \multicolumn{1}{c}{ Variáveis } & Média & $\begin{array}{c}\text { Desvio } \\
\text { Padrão }\end{array}$ & $\begin{array}{c}\text { Coef. De } \\
\text { Variação }\end{array}$ & Máximo & Mínimo & Mediana & Curtose & Assim. \\
\hline $\begin{array}{l}\text { Valor da produção de lavoura } \\
\text { temporária (mil R\$) }\end{array}$ & 799 & 1.894 & 2,37 & 18.838 & 1,00 & 272 & 63,62 & 7,01 \\
\hline $\begin{array}{l}\text { Produção vegetal (t) } \\
\text { Valor da produção animal (mil R\$) }\end{array}$ & 1.366 & 3.214 & 2,35 & 28.202 & 0,26 & 445 & 40,89 & 5,55 \\
\hline $\begin{array}{l}\text { Valor da produção de animais de } \\
\text { grande porte (mil R\$) }\end{array}$ & 649 & 571 & 0,88 & 3.205 & 19,00 & 489 & 7,34 & 1,87 \\
\hline Pronaf & 530 & 544 & 1,03 & 2.768 & 7,97 & 365 & 6,68 & 1,87 \\
\hline $\begin{array}{l}\text { Mão de obra familiar em lavouras } \\
\text { temporárias (pessoas) }\end{array}$ & 230 & 235 & 1,02 & 1.336 & 1,00 & 166 & 8,02 & 1,97 \\
\hline $\begin{array}{l}\text { Mão de obra familiar na pecuária e } \\
\text { outros animais (pessoas) }\end{array}$ & 969 & 1.150 & 1,19 & 9.445 & 31,00 & 676 & 32,54 & 4,82 \\
\hline
\end{tabular}

Fonte: Elaboração própria a partir de dados do Censo Agropecuário de 2006 (IBGE, 2012) e SAF/MDA (2012).

existindo, inclusive, linhas de crédito específicas para eles $^{20}$.

Nessa linha, percebe-se também que a distribuição dos recursos do Pronaf entre as microrregiões do estado guarda certa correspondência com a produção dos principais produtos da agricultura familiar - arroz, feijão e milho - que, conforme já enfatizado, compõem a base alimentar da população brasileira. Em 2006, a produção conjunta desses três produtos foi de 142,2 mil toneladas. A microrregião com o menor recebimento de recursos à época, Jalapão $(4,1 \%)$, foi também a que menos contribuiu na produção conjunta desses produtos. De outro lado, a Microrregião do Bico do Papagaio, que ficava com a segunda maior fatia do crédito $(19,4 \%)$, respondia pela segunda maior produção conjunta $(22,8 \%)$.

\subsection{Pronaf e produção da agricultura familiar}

As estatísticas descritivas das variáveis da agricultura familiar (Tabela 1) permitem conhecer algumas das características desse segmento produtivo, público-alvo do Pronaf. Embora os dados se restrinjam ao ano do último Censo Agropecuário (2006), dado o maior nível de deta-

20. Pronaf Grupo "A" é o crédito para os assentados da reforma agrária destinado à estruturação de suas unidades produtivas e Pronaf Grupo "A/C" é o crédito de custeio para as famílias assentadas da reforma agrária que já receberam financiamento do Grupo " $\mathrm{A}$ ", conforme disposto na Resolução CMN/Bacen/Nº 4.107/2012 (BACEN, 2012). lhamento das informações, eles possibilitam um retrato mais bem definido da produção agrícola familiar no estado do Tocantins.

A desigualdade verificada entre os municípios (unidades de análise) no que se refere às variáveis dependentes torna menos indicada a análise econométrica por meio da Regressão Linear pela Média (RLM), de modo que os coeficientes obtidos por este método constam das tabelas de resultados apenas como referência e não foram objeto de análise mais acurada. Observa-se que as distribuições de todas as variáveis têm assimetria positiva ou à direita (assimetria $>0$ ) e são leptocúrticas (curtose $>3$ ), isto é, suas curvas apresentam formato mais agudo na parte superior. De acordo com o teste Jarque-Bera, ao nível de $1 \%$ de significância, nenhuma das variáveis dependentes apresenta distribuição normal, justificando o uso da Regressão Quantílica (RQ), ou, dito de outra forma, o uso de RLM não é capaz de informar sobre o centro da distribuição. No presente caso, além de informar sobre aquele centro (mediana), a RQ permite observar os efeitos das variáveis explicativas (Pronaf e mão de obra familiar) ao longo de toda distribuição de probabilidade das variáveis dependentes (valor da produção de lavoura temporária, volume da produção vegetal, valor da produção animal e valor da produção de animais de grande porte). Importante também reprisar que, como os modelos econométricos foram especificados em duplo- 
-log, os coeficientes medem elasticidades, ou seja, a variação percentual na variável dependente em questão, dada uma variação percentual em uma das variáveis explicativas.

Em todas as regressões os sinais dos coeficientes das variáveis explicativas foram os esperados, isto é, tanto o Pronaf quanto a mão de obra familiar apresentaram relação positiva com as variáveis de produção. Na maioria dos casos, as variáveis explicativas mostraram-se estatisticamente significantes ao nível de $1 \%$ ou $5 \%$, mas admitiu-se como significante até o nível de 10\%, de maneira que os poucos coeficientes que não atenderam essa premissa não foram considerados nas análises.

Quando a variável dependente é o valor das lavouras temporárias (lnvalorLT), Tabela 2, os coeficientes estimados sugerem que, dada uma variação de $1 \%$ no Pronaf (Inpronaf), haveria uma variação positiva de $0,40 \%, 0,36 \%, 0,29 \%$ e $0,27 \%$ para o décimo percentil, para o primeiro quartil, para a mediana e para o nonagésimo percen- til, respectivamente. Verifica-se, portanto, que o efeito positivo do Pronaf sobre o valor das lavouras temporárias é positivo e mais intenso nos municípios de menor produção.

No caso da mão de obra familiar, como era de se esperar, os resultados foram ainda mais contundentes, sendo que no décimo percentil o efeito dessa variável explicativa sobre a variável dependente é mais que proporcional, pois o coeficiente estimado indica que o aumento no valor da produção de lavouras temporárias supera o acréscimo de $1 \%$ no quantitativo de mão de obra (lnmobLT).

Para a variável dependente produção vegetal $(\ln p P V)$, como detalhado na Tabela 3, os coeficientes estimados indicam que, dada uma variação de $1 \%$ no Pronaf (lnpronaf), haveria variação positiva de $0,53 \%, 0,31 \%, 0,26 \%$ e $0,32 \%$ para o décimo percentil, para o primeiro quartil, para a mediana e para o terceiro quartil, respectivamente. Também neste caso, o efeito positivo do Pronaf sobre a produção vegetal é mais intenso

Tabela 2. Resultados das regressões de RLM e RQ para 2006

\begin{tabular}{|c|c|c|c|c|c|c|}
\hline \multirow{3}{*}{$\begin{array}{c}\text { Variáveis } \\
\text { independentes }\end{array}$} & \multicolumn{6}{|c|}{ Variável dependente: $\operatorname{lnvalor} L T$} \\
\hline & \multirow{2}{*}{ RLM } & \multicolumn{5}{|c|}{ RQs } \\
\hline & & Q.10 & $Q .25$ & Q.50 & $Q .75$ & Q.90 \\
\hline lnpronaf & 0,3365 & 0,4058 & 0,3676 & 0,2901 & 0,2689 & 0,2711 \\
\hline Valor-p & 0,0000 & 0,0540 & 0,0070 & 0,0110 & 0,1670 & 0,0100 \\
\hline $\operatorname{lnmobLT}$ & 0,9056 & 1,0929 & 0,9667 & 0,7866 & 0,7797 & 0,8356 \\
\hline Valor-p & 0,0000 & 0,0000 & 0,0000 & 0,0000 & 0,0000 & 0,0000 \\
\hline Cons & 3,6565 & 0,2925 & 2,1590 & 4,8636 & 5,8448 & 6,3603 \\
\hline Valor-p & 0,0020 & 0,9060 & 0,1380 & 0,0000 & 0,0070 & 0,0000 \\
\hline $\mathbf{R}^{2}$ & 0,53 & 0,42 & 0,31 & 0,27 & 0,25 & 0,29 \\
\hline
\end{tabular}

Fonte: Estimativas próprias a partir de dados do Censo Agropecuário de 2006 (IBGE, 2012) e da SAF/MDA (2012). N = 139.

Tabela 3. Resultados das regressões de RLM e RQ para 2006

\begin{tabular}{|c|c|c|c|c|c|c|}
\hline \multirow{3}{*}{$\begin{array}{c}\text { Variáveis } \\
\text { independentes }\end{array}$} & \multicolumn{6}{|c|}{ Variável dependente: $\operatorname{In} p P V$} \\
\hline & \multirow{2}{*}{ RLM } & \multicolumn{5}{|c|}{ RQs } \\
\hline & & Q.10 & $Q .25$ & $Q .50$ & $Q .75$ & Q.90 \\
\hline lnpronaf & 0,2661 & 0,5324 & 0,3172 & 0,2642 & 0,3279 & 0,3876 \\
\hline Valor-p & 0,0140 & 0,0240 & 0,0260 & 0,0020 & 0,0380 & 0,2850 \\
\hline $\operatorname{lnmobLT}$ & 1,0538 & 1,1514 & 0,8226 & 0,9189 & 0,8144 & 0,9423 \\
\hline Valor-p & 0,0000 & 0,0000 & 0,0020 & 0,0000 & 0,0000 & 0,0000 \\
\hline Cons & 4,2133 & $-1,1961$ & 3,9538 & 4,9084 & 5,3435 & 4,7305 \\
\hline Valor-p & 0,0000 & 0,6790 & 0,0390 & 0,0000 & 0,0010 & 0,2790 \\
\hline $\mathbf{R}^{2}$ & 0,55 & 0,46 & 0,35 & 0,31 & 0,28 & 0,26 \\
\hline
\end{tabular}

Fonte: Estimativas próprias a partir de dados do Censo Agropecuário de 2006 (IBGE, 2012) e da SAF/MDA (2012). N = 139. 
no décimo percentil, diminui até a mediana e volta a subir no terceiro quartil. Vale registrar também que, com exceção da produção de soja, da qual a agricultura familiar tocantinense participa com apenas $1,5 \%$, as demais variáveis ocupam mais de $95 \%$ da área colhida do grupo aqui definido como produção vegetal - arroz (50\%), milho $(30,6 \%)$, mandioca $(8 \%)$, feijão $(7,2 \%)-\mathrm{e}$ constituem a base alimentar da população.

Os resultados para a variável explicativa mão de obra familiar são semelhantes àqueles obtidos para o valor das lavouras temporárias. Novamente, o efeito mais forte ocorre no décimo percentil, no qual chega a ser mais que proporcional. Especificamente, os estimadores sugerem que, diante de uma variação de $1 \%$ no quantitativo de mão de obra (lnmobLT), haveria uma variação positiva de $1,15 \%, 0,82 \%, 0,91 \%, 0,81 \%$ e $0,94 \%$ para o décimo percentil, para o primeiro quartil, para a mediana, para o terceiro quartil e para o nonagésimo percentil, respectivamente.

Para a variável dependente valor da produção animal (lnvalorPA), como destacado na Tabela 4, os resultados sugerem que, dada uma variação de $1 \%$ no Pronaf (Inpronaf), a produção teria elevação de $0,59 \%, 0,31 \%, 0,24 \%, 0,30 \%$ e $0,24 \%$ no décimo percentil, no primeiro quartil, na mediana, no terceiro quartil e no nonagésimo percentil, respectivamente. Nesse caso, observaram-se diferenças importantes no comportamento da variável explicativa mão de obra familiar. Embora continue tendo alto poder expli- cativo em relação à produção, a variável apresentou efeitos menores comparativamente ao que se verificou quando a variável resposta pertencia ao grupo das lavouras. Além disso, apresentou efeitos crescentes à medida que se eleva o volume de produção municipal, revelando-se estatisticamente significante somente a partir do primeiro quartil. Os coeficientes apontam que a variação de $1 \%$ no quantitativo de mão de obra (lnmobPA) provocaria variação positiva de $0,40 \%, 0,53 \%$, $0,54 \%$ e $0,57 \%$ para o primeiro quartil, para a mediana, para o terceiro quartil e para o nonagésimo percentil, respectivamente.

Conforme detalhado na Tabela 5, considerando apenas os animais de grande porte (lnvalo$r A G P$ ) como variável dependente, uma variação de $1 \%$ no Pronaf (Inpronaf) reflete elevação de $0,38 \%, 0,24 \%, 0,27 \%$ e $0,21 \%$ no décimo percentil, na mediana, no terceiro quartil e no nonagésimo percentil, respectivamente. No caso da mão de obra (lnmobPA), elevação de $1 \%$ sugere aumento $0,53 \%, 0,55 \%, 0,55 \%$ e $0,62 \%$ no primeiro quartil, na mediana, no terceiro quartil e no nonagésimo percentil, respectivamente. Verificou-se que, em ambas as variáveis explicativas - Pronaf e mão de obra familiar - os resultados entre o valor da produção animal e o valor da produção de animais de grande porte foram bastante semelhantes, indicando que este último seria representativo do primeiro, o que se mostra plausível dada a participação dessa variável na receita total da produção animal (Tabela 1).

Tabela 4. Resultados das regressões de RLM e RQ para 2006

\begin{tabular}{|c|c|c|c|c|c|c|}
\hline \multirow{3}{*}{$\begin{array}{c}\text { Variáveis } \\
\text { independentes }\end{array}$} & \multicolumn{6}{|c|}{ Variável dependente: InvalorPA } \\
\hline & \multirow{2}{*}{ RLM } & \multicolumn{5}{|c|}{ RQs } \\
\hline & & Q.10 & Q.25 & Q.50 & Q.75 & Q.90 \\
\hline lnpronaf & 0,3452 & 0,5941 & 0,3147 & 0,2450 & 0,3014 & 0,2467 \\
\hline Valor-p & 0,0000 & 0,0220 & 0,0040 & 0,0000 & 0,0010 & 0,0530 \\
\hline $\operatorname{lnmobPA}$ & 0,3916 & 0,2597 & 0,4009 & 0,5360 & 0,5406 & 0,5715 \\
\hline Valor-p & 0,0100 & 0,3870 & 0,0010 & 0,0000 & 0,0000 & 0,0080 \\
\hline Cons & 6,3932 & 3,3900 & 6,5078 & 6,7969 & 6,2673 & 7,1387 \\
\hline Valor-p & 0,0000 & 0,2130 & 0,0000 & 0,0000 & 0,0000 & 0,0000 \\
\hline $\mathbf{R}^{2}$ & 0,48 & 0,26 & 0,34 & 0,40 & 0,37 & 0,27 \\
\hline
\end{tabular}

Fonte: Estimativas próprias a partir de dados do Censo Agropecuário de 2006 (IBGE, 2012) e da SAF/MDA (2012). N = 139. 
Tabela 5. Resultados das regressões de RLM e RQ para 2006

\begin{tabular}{|c|c|c|c|c|c|c|}
\hline \multirow{3}{*}{$\begin{array}{c}\text { Variáveis } \\
\text { independentes }\end{array}$} & \multicolumn{6}{|c|}{ Variável dependente: $\operatorname{lnvalorAGP}$} \\
\hline & \multirow{2}{*}{ RLM } & \multicolumn{5}{|c|}{ RQs } \\
\hline & & Q.10 & $Q .25$ & Q.50 & Q.75 & Q.90 \\
\hline lnpronaf & 0,3138 & 0,3873 & 0,2307 & 0,2441 & 0,2715 & 0,2131 \\
\hline Valor-p & 0,0000 & 0,0530 & 0,1540 & 0,0000 & 0,0000 & 0,0970 \\
\hline $\operatorname{lnmobPA}$ & 0,4293 & 0,3768 & 0,5378 & 0,5509 & 0,5578 & 0,6241 \\
\hline Valor-p & 0,0050 & 0,1980 & 0,0030 & 0,0000 & 0,0000 & 0,0580 \\
\hline Cons & 6,2826 & 4,9250 & 6,3940 & 6,4294 & 6,2850 & 7,0282 \\
\hline Valor-p & 0,0000 & 0,0200 & 0,0000 & 0,0000 & 0,0000 & 0,0000 \\
\hline $\mathbf{R}^{2}$ & 0,47 & 0,25 & 0,31 & 0,38 & 0,35 & 0,25 \\
\hline
\end{tabular}

Fonte: Estimativas próprias a partir de dados do Censo Agropecuário de 2006 (IBGE, 2012) e da SAF/MDA (2012). N = 139.

Tomando as variáveis valor das lavouras temporárias (lnvalorLT) e volume da produção vegetal $(\ln p P V)$ e valor da produção animal (lnvalorPA) e valor da produção de animais de grande porte (lnvalorAGP) como pares, respectivamente, representativos da produção vegetal total e da produção animal total, observa-se o seguinte: tendo como foco a produção vegetal, o Pronaf apresenta efeitos positivos que variam de $0,26 \%$ a $0,53 \%$, com maior influência nos municípios de menor produção. Já os efeitos da variável mão de obra variam de $0,77 \%$ a $1,15 \%$, apresentando comportamento mais equilibrado entre os diversos percentis de distribuição da produção, sobretudo a partir do primeiro quartil.

De modo análogo, focando-se na produção animal, no caso do Pronaf nota-se, a exemplo do que ocorre com a produção vegetal, que o maior efeito está nos municípios de menor produção, só que variando ainda mais, entre $0,21 \%$ e 0,59\%. Na mão de obra, a variação é menor (de $0,40 \%$ a $0,62 \%$ ) e, diferente do comportamento do Pronaf, os coeficientes não são maiores nos municípios de menor produção. Importante observar que, a partir do primeiro quartil, os efeitos do Pronaf na produção animal são menores que na produção vegetal. Parte desta distinção certamente pode ser explicada pela diferença de tempo de resposta ao estímulo creditício existente entre essas variáveis, de modo que, provavelmente, os resultados na produção animal poderiam ter sido mais robustos se fosse considerado algum nível de defasagem que captasse o efeito de médio prazo.
A diferença entre coeficientes da mão de obra quando se confrontam os dois tipos de produção são ainda maiores, o que também não causa surpresa, tendo em vista que a produção vegetal é comparativamente mais intensiva em trabalho.

Por fim, registra-se que, apesar de os efeitos do Pronaf se revelarem positivos e significativos, em todos os modelos analisados a mão de obra familiar apresentou alto poder explicativo sobre os resultados produtivos, superando os efeitos do crédito. Isso mostra que, conforme abordado na literatura, o trabalho familiar é decisivo para o desempenho produtivo da unidade de produção familiar e que, embora importante, a política pública tem apenas caráter complementar no processo produtivo.

\section{Conclusões}

Este artigo teve por objetivo avaliar a capacidade do Pronaf, na qualidade de política pública, de contribuir para a redução do hiato entre o potencial produtivo e o produto efetivo da agropecuária tocantinense. Para tanto, foram analisadas a cobertura do programa, a distribuição de seus recursos pelo território estadual, assim como as relações entre o volume de crédito do Pronaf e variáveis da produção agrícola de origem familiar dos municípios tocantinenses (unidades de análise), empregando-se, sobretudo, métodos econométricos.

Observou-se que o Pronaf se consubstancia na primeira política pública exclusiva da agri- 
cultura familiar, tendo contribuído tanto para a consolidação do conceito de agricultura familiar no Brasil quanto para conferir à categoria legitimidade social e reconhecimento como segmento produtivo. Esse reconhecimento político do agricultor familiar representou uma ruptura em relação à postura do Estado brasileiro ao longo do processo de modernização da agricultura, que, diferente do que se verificou em países desenvolvidos, privilegiou em suas intervenções a agricultura fundada na grande propriedade e no trabalho assalariado em detrimento da unidade de produção familiar. Embora o Pronaf represente, assim, uma guinada nas estratégias de desenvolvimento rural, alterando de modo significativo o ambiente institucional em favor da agricultura de base familiar, constatou-se necessidade de estudos que avaliem o desempenho do programa em termos de influência sobre os resultados econômicos e agrícolas, especialmente nos espaços regionais/locais.

No Tocantins, percebeu-se, de um lado, uma nítida tendência de evolução do programa entre 2002 e 2009, seja em termos de cobertura territorial ou de volume de recursos. Em 2009, praticamente todos os municípios já participavam do programa e o montante de recursos chegou a $\mathrm{R} \$$ 134 milhões, valor significativo para as dimensões da economia tocantinense. Embora exista espaço para a expansão, dado o quantitativo de estabelecimentos familiares no Tocantins, bem como para possíveis aperfeiçoamentos na distribuição dos recursos, verificou-se presença do Pronaf mesmo nos municípios mais pobres e distantes da capital, não havendo evidências de que os créditos do programa estejam escorrendo para as microrregiões mais ricas. Pelo contrário, existe significativa participação de microrregiões pobres e a correspondência entre a distribuição dos recursos e a localização de estabelecimentos familiares e de assentamentos da reforma agrária, o que depõe a favor da focalização do Pronaf. De outro lado, as análises apontam resultados positivos do Pronaf em relação às variáveis da dimensão produtiva da agricultura familiar. Em termos específicos, as estimações sugerem que o crédito estimula a pro- dução vegetal e animal da agricultura familiar, que, no Tocantins, a exemplo do que ocorre no Brasil, tem substantiva participação na produção total do setor agrícola.

Dessa forma, os resultados obtidos permitem afirmar que o Pronaf como política pública reúne condições para contribuir para a redução do hiato entre o potencial produtivo e o produto efetivo da agropecuária tocantinense. Além disso, dadas as especificidades do programa no estado em termos de cobertura e distribuição dos recursos, supõe-se que as constatações confiram ao Pronaf características para também contribuir na redução da desigualdade no estado, que, apesar de ficar abaixo da média nacional, ainda é muito alta.

Apesar do fato de os resultados apontarem efeitos positivos da intervenção estatal consubstanciada na política pública de crédito, é importante ressaltar que o trabalho familiar, como apresentado na literatura revisada, mostrou-se decisivo no desempenho da unidade de produção familiar no âmbito do estado do Tocantins. Desse modo, atribui-se ao mecanismo de crédito (Pronaf) um papel importante, que merece atenção dos formuladores de políticas (policy makers), porém de caráter complementar, qual seja, estimular a produção agrícola de unidades produtivas fundadas no trabalho da família.

\section{Referências bibliográficas}

ABRAMOVAY, R. Paradigmas do capitalismo agrário em questão. São Paulo: Hucitec, 1992.

ABRAMOVAY, R. e VEIGA, J. E. da. Novas instituições para o desenvolvimento rural: o caso do Programa Nacional de Fortalecimento da Agricultura Familiar (Pronaf). Brasília: IPEA, 1999.

AQUINO, J. R. de e TEIXEIRA, O. A. Agricultura familiar, crédito e mediação institucional: a experiência do PRONAF em São Miguel, no Nordeste Brasileiro. Revista Cuadernos de Desarrollo Rural, Bogotá, v. 2, n. 54, 2005.

BACEN. Resolução no 4.107, de 28 de junho de 2012, que altera as disposições do Pronaf, Cap. 10 do Manual de Crédito Rural, para aplicação a partir da safra 2012/2013. 2012. Disponível em: <http://www.bcb.gov.br>. Acesso em: 18 set. 2012. 
BACHA, C. J. C. Economia e política agrícola no Brasil. São Paulo: Atlas, 2004.

BITTENCOURT, G. A. Abrindo a caixa preta: o financiamento da agricultura familiar no Brasil. Campinas: Dissertação de Mestrado, IE/Unicamp, 2003.

BRASIL. Decreto no 1.946, de 28 de junho de 1996, que cria o Programa Nacional de Fortalecimento da Agricultura Familiar (Pronaf). 1996. Disponível em: <http://www. planalto.gov.br>. Acesso em: 20 jul. 2012.

BUAINAIN, A. M., ROMEIRO, A. R. e GUANZIROLI, C. E. Agricultura Familiar e o Novo Mundo Rural. Revista Sociologias, Porto Alegre, ano 5, n. 10, p. 312-347, jul/dez. 2003.

CONTI, B. M. de e ROITMAN, F. B. Pronaf: uma análise da evolução das fontes de recursos utilizadas no programa. Revista do BNDES 35, p. 131-168, jun. 2011.

DELGADO, G. C. A questão agrária no Brasil, 19502003. In: JACCOUD, L. (Org.). Questão social e políticas sociais no Brasil contemporâneo. Brasília: IPEA, 2005.

FAO. Novo retrato da agricultura familiar: o Brasil redescoberto. Brasília, 2000.

FRAZÃO FILHO, F. A. e MORAES, M. D. C. de. Migração temporária e Pronaf na trajetória social de famílias camponesas. In: Anais Congresso Latinoamericano de Sociologia Rural, Porto de Galinhas/PE, 2010.

GASQUES, J. G., FREITAS, R. E., BASTOS, E. T., SILVA, H. D. P. da e SILVA, A. R. da. Agricultura familiar Pronaf: análise de alguns indicadores. 2005. Disponível em: $<$ http://www.sober.org.br/palestra/2/504.pdf $>$. Acesso em: 18 jun. 2012.

GAZOLLA, M. e SCHNEIDER, S. As duas "caras" do Pronaf: produtivismo ou fortalecimento da produção para o autoconsumo? In: Anais do Congresso da SOBER, Ribeirão Preto/SP, 2005.

GOLGHER, A. B. e MARQUES, D. H. F. A migração urbano/urbano, rural/urbano, urbano/rural e rural/ rural no Brasil: a busca de padrões e diferenças implicações para a pobreza rural 2006. In: Anais do Encontro Nacional de Estudos Populacionais (ABEP), Caxambu/MG, 2006.

GUANZIROLI, C. E., ROMEIRO, A., BUAINAIN, A. M., SABBATO, A. di e BITTENCOURT, G. Agricultura familiar e reforma agrária no século XXI. Rio de Janeiro: Garamondi, 2001.

GUANZIROLI, C. E. Pronaf dez anos depois: resultados e perspectivas para o desenvolvimento rural. Revista de Economia e Sociologia Rural, Rio de Janeiro, v. 45, n. 2, p. 301-328, abr/jul. 2007.
GUJARATI, D. N. Econometria básica. São Paulo: Makron Books, 2006.

HAO, L. e NAIMAN, D. Quantile regression. Thousand Oaks: Sage, 2007.

IBGE. Censo Agropecuário 2006: agricultura familiar primeiros resultados. Rio de Janeiro: IBGE, 2009.

IBGE. Censo Agropecuário 2006: Brasil, Grandes Regiões e Unidades da Federação. 2011. Disponível em: < http://www. ibge.gov.br/home/estatistica/economia/agropecuaria/ censoagro/default.shtm > . Acesso em: 12 nov. 2011.

IBGE. Sistema IBGE de Recuperação Automática (Sidra). 2012. Disponível em: <http://www.ibge.gov.br> Acesso em: 18 mar. 2012.

INCRA. Sistema de Informações de Projetos de Reforma Agrária. Palmas: Incra, 2012.

KAGEYAMA, Â. Produtividade e renda na agricultura familiar: efeitos do Pronafrédito. Revista Agricultura em São Paulo, São Paulo: IEA, v. 50, n. 2, jul./dez. 2003.

MAGALHÃES, A. M., SILVEIRA NETO, R., DIAS, F. de M. e BARROS, A. R. A experiência recente do Pronaf em Pernambuco: uma análise através de propensity score. Revista Economia Aplicada [online], v. 10, n. 1, p. 57-74, Ribeirão Preto/SP, 2006.

MATTEI, L. Impactos do Pronaf: análise de indicadores. MDA, Núcleo de Estudos Agrários e Desenvolvimento Rural. Brasília: NEAD, 2005.

MATTEI, L. Programa Nacional de Fortalecimento da Agricultura Familiar (Pronaf): concepção, abrangência e limites observados. In: Anais do Encontro da Sociedade Brasileira de Sistemas de Produção, realizado em Belém/ PA, 2001.

MATTEI, L. Pronaf 10 anos: mapa da produção acadêmica. Ministério do Desenvolvimento Agrário, Núcleo de Estudos Agrários e Desenvolvimento Rural. Brasília: MDA, 2006.

MATTEI, L., WAQUIL, P., SCHNEIDER, S., CONTERATO, M., RADOMSKY, G., NAMIZAKI, G. e NIEDERLE, S. Uma análise dos impactos do Pronaf sobre as economias locais nas regiões Nordeste, Sudeste e Norte do Brasil. In: Anais do Congresso da SOBER, Londrina/PR, 2007.

NORTH, D. C. Custos de transação, instituições e desempenho econômico. Rio de Janeiro: Instituto Liberal, 1994.

SACCO DOS ANJOS, F., GODOY, W. I., CALDAS, N. V. e GOMES, M. C. Agricultura familiar e políticas públicas: o impacto do Pronaf no Rio Grande do Sul. Revista de Economia e Sociologia Rural, Rio de Janeiro, n. 3, p. 529-548, jul/set. 2004. 
156 - Efeitos do Pronaf sobre a Produção Agrícola Familiar dos Municípios Tocantinenses

SAF/MDA. Banco de dados do Pronaf. Brasília, 2012.

SCHNEIDER, S. A pluriatividade na agricultura familiar. Porto Alegre: UFRGS, 2003.

SCHUMPETER, J. A. Teoria do desenvolvimento econômico: Uma investigação sobre lucros, capital, crédito, juro e o ciclo econômico. São Paulo: Nova Cultural, 1997.
SIC. Agronegócio. 2012. Disponível em: <http://sic. to.gov.br/conteudo.php?id=8>. Acesso em: 2 de junho de 2012 .

SILVA, S. P. e ALVES FILHO, E. Impactos econômicos do Pronaf em territórios rurais: um estudo para o Médio Jequitinhonha - MG. Revista Econômica do Nordeste, Fortaleza, v. 40, n. 3, p. 481-498, jul/set. 2009. 